\title{
Simulations Based on Experimental Data of the Behaviour of a Monocrystalline Silicon Photovoltaic Module
}

\author{
Abraham Dandoussou, ${ }^{1}$ Martin Kamta, ${ }^{2}$ Laurent Bitjoka, \\ Patrice Wira, ${ }^{3}$ and Alexis Kuitché ${ }^{2}$ \\ ${ }^{1}$ Department of Electrical and Power Engineering, Higher Technical Teachers' Training College (HTTTC), University of Buea, \\ Kumba, Cameroon \\ ${ }^{2}$ Department of Electrical, Energetic and Automatic Engineering, ENSAI, University of Ngaoundere, Ngaoundere, Cameroon \\ ${ }^{3}$ Laboratory of Modeling, Intelligence, Process and Systems (MIPS), University of Haute Alsace, 61 Road Albert Camus, \\ 68093 Mulhouse Cedex, France
}

Correspondence should be addressed to Abraham Dandoussou; dandoussou@gmail.com

Received 26 June 2015; Accepted 12 August 2015

Academic Editor: Santanu Bandyopadhyay

Copyright (C) 2015 Abraham Dandoussou et al. This is an open access article distributed under the Creative Commons Attribution License, which permits unrestricted use, distribution, and reproduction in any medium, provided the original work is properly cited.

\begin{abstract}
The performance of monocrystalline silicon cells depends widely on the parameters like the series and shunt resistances, the diode reverse saturation current, and the ideality factor. Many authors consider these parameters as constant while others determine their values based on the $I-V$ characteristic when the module is under illumination or in the dark. This paper presents a new method for extracting the series resistance, the diode reverse saturation current, and the ideality factor. The proposed extraction method using the least square method is based on the fitting of experimental data recorded in 2014 in Ngaoundere, Cameroon. The results show that the ideality factor can be considered as constant and equal to 1.2 for the monocrystalline silicon module. The diode reverse saturation current depends only on the temperature. And the series resistance decreases when the irradiance increases. The extracted values of these parameters contribute to the best modeling of a photovoltaic module which can help in the accurate extraction of the maximum power.
\end{abstract}

\section{Introduction}

The world energetic consumption is still dominated by the use of nonconventional sources like fossil sources, natural gases, and nuclear sources. The main drawback of the use of these sources is that they are exhaustible and they contribute to the pollution of the environment. Hence, it is useful to use renewable energy sources such as biomass, wind energy, hydroelectricity, and solar energy. Solar energy occupies an important place because it is available everywhere. Photovoltaic energy which is based on the conversion of direct sunlight into electricity is the most promising one. There are different technologies of photovoltaic (PV) cells which are found on the market: monocrystalline silicon (efficiency of $25 \pm 0.5 \%$ ), polycrystalline silicon (efficiency of $20.4 \pm 0.5 \%$ ), amorphous silicon (efficiency of $10.1 \pm 0.3 \%$ ), and organic solar cells (laboratory efficiency of $8.3 \pm 0.3 \%$ ) $[1,2]$.
However, the performance of a photovoltaic cell is influenced by the climatic and meteorological conditions such as the irradiance and the temperature. It is known in the literature that when the irradiance decreases, the current also decreases and consequently, the output power decreases. When the temperature increases, the voltage decreases and the output power also decreases $[3,4]$. Some authors [4, 5] stated that the photovoltaic parameters like the series resistance, the diode ideality factor, and the diode reverse saturation current influence the performance of the PV cell. The diode reverse saturation current has been modeled by an equation showing its dependence on the temperature [5]. But the other parameters have not been in the center of a particular study for a mathematical model. Nevertheless, these parameters and the diode reverse saturation current have been determined by some authors [3-8]. These authors measured the $I-V$ characteristic of a PV module using a 
solar simulator instead of the normal operating conditions. Under the real weather conditions, it is difficult to have a constant irradiance and a constant temperature, particularly in the tropical climate. So, it is not evident to get the $I-V$ characteristic of the PV module under the normal weather conditions. That is why this paper proposes a new method of the determination of photovoltaic parameters under the normal operating conditions. The irradiance, the temperature, the load current, and the load voltage have been recorded during a whole day. Then, the PV parameters have been calculated from these experimental data using a least square method in the PV parameters extraction algorithm. The results confirm that the diode reverse saturation current $I_{S}$ effectively depends on the temperature and the mathematical expression obtained in the literature has been validated [69]. The diode ideality factor, $n$, changes less with the weather conditions. The series resistance $R_{s}$ depends essentially on the irradiance. The mathematical expression of the series resistance has been obtained.

In order to verify the effectiveness of these results, the PV module has been modeled with MATLAB/SIMULINK. The input parameters for the simulations are the recorded irradiance and surface temperature, the determined PV parameters $\left(R_{s}, I_{S}\right.$, and $\left.n\right)$. The recorded load current has been also loaded in the SIMULINK model for comparison. For the comparison with the literature results, the same PV module model has been simulated as inputs: the recorded irradiance and temperature, a constant diode ideality factor $(n=1.2)$, a constant series resistor $\left(R_{s}=2.1 \Omega\right)$, and the diode reverse saturation current expression. The results show that the PV module modeled with the variable PV parameters is more accurate than the one modeled with the constant series resistance and the constant diode ideality factor. These simulation results show the real behaviour of the PV module under the normal operating conditions. Consequently, the obtained model can be used for the extraction of the maximum power of the PV module, under the normal weather conditions.

This paper is divided into the following sections: the first section presents research method including the modeling of a photovoltaic cell, the experiment, and the extraction algorithm of PV module parameters and the second section presents the results and analysis.

\section{Research Method}

2.1. Modeling of a Photovoltaic Cell. Two electrical models are used for modeling a photovoltaic cell:

(i) A two-diode model (TDM) with the second diode which represents the recombination phenomenon in the bulk cell. However, this model is generally used for a polycrystalline silicon cell [10-12].

(ii) A one diode model (ODM) which is simple and represents precisely the operation of a monocrystalline solar cell [5-13]. This model which is used in this work is presented in Figure 1 with $D$, a diode which represents the $P-N$ junction; $R_{s}$ and $R_{p}$ are the series

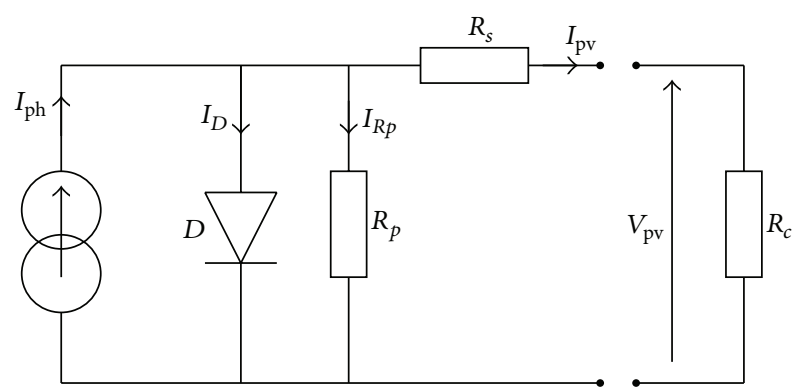

FIGURE 1: One diode (ODM) of a photovoltaic cell.

and shunt resistances. By applying Kirchhoff's laws, the following equation is obtained:

$$
\begin{aligned}
I_{\mathrm{pv}}= & I_{\mathrm{ph}}-I_{S}\left(\exp \left(\frac{q\left(V_{\mathrm{pv}}+R_{s} I_{\mathrm{pv}}\right)}{n k T_{C}}\right)-1\right) \\
& -\frac{V_{\mathrm{pv}}+R_{s} I_{\mathrm{pv}}}{R_{p}} .
\end{aligned}
$$

Due to the fact that $R_{p}$ is higher than $R_{s}\left(R_{p} \gg R_{s}\right)$ and its influence on the performance of the PV cell is insignificant [5-13], (1) becomes

$$
I_{\mathrm{pv}}=I_{\mathrm{ph}}-I_{S}\left(\exp \left(\frac{\left(V_{\mathrm{pv}}+R_{s} I_{\mathrm{pv}}\right)}{n V_{t}}\right)-1\right),
$$

where

(i) $n$ is the diode ideality factor;

(ii) $V_{t}=k T_{C} / q$ is the thermal voltage;

(iii) $q=1.60 \times 10^{-19} \mathrm{C}$ is the electrical charge;

(iv) $k=1.38 \times 10^{-23} \mathrm{~J} / \mathrm{K}$ is the Boltzmann constant;

(v) $T_{C}$ is the surface PV cell temperature $(\mathrm{K})$;

(vi) $I_{S}$ is the diode reverse saturation current (A).

Equation (2) is a nonlinear expression of $I_{\mathrm{pv}}$ because it expresses $I_{\mathrm{pv}}$ in function of $I_{\mathrm{pv}}$ and $V_{\mathrm{pv}}$. In order to obtain a linear expression of $I_{\mathrm{pv}}$, the Lambert $W$ function can be used. In fact, the Lambert $W$ function is used to solve nonlinear equation as $w(x) e^{w(x)}=x$.

By applying this function to (2), the linear form of $I_{\mathrm{pv}}$ is given by (3). Consider

$$
\begin{aligned}
I_{\mathrm{pv}} & =I_{S}+I_{\mathrm{ph}}-\frac{n V_{t}}{R_{s}} \\
\cdot & \text { Lambert } W\left[\frac{R_{s} I_{S}}{n V_{t}} \exp \left(\frac{V_{\mathrm{pv}}+R_{s} I_{\mathrm{ph}}+R_{s} I_{S}}{n V_{t}}\right)\right] \\
I_{\mathrm{ph}} & =\frac{G}{G_{\text {ref }}}\left(I_{\text {scref }}+K_{I}\left(T_{C}-T_{\text {Cref }}\right)\right),
\end{aligned}
$$

where

(i) $G$ is the irradiance $\left(\mathrm{W} / \mathrm{m}^{2}\right)$;

(ii) $G_{\text {ref }}=1000 \mathrm{~W} / \mathrm{m}^{2}$ is the reference irradiance. 
TABLE 1: Manufacture's specifications of Solar H750 Helios Module.

\begin{tabular}{lc}
\hline Band gap energy of silicon at $300 \mathrm{~K}$ & $1.12 \mathrm{eV}$ \\
Ideality factor of the $P-N$ junction & 1.2 \\
Short circuit current at STC & $4.01 \mathrm{~A}$ \\
Open circuit voltage at STC & $21.6 \mathrm{~V}$ \\
Current at MPP & $3.47 \mathrm{~A}$ \\
Voltage at MPP & $17.3 \mathrm{~V}$ \\
Maximum power at STC & $60 \mathrm{Wp}$ \\
Number of series-connected cells & 36 \\
\hline
\end{tabular}

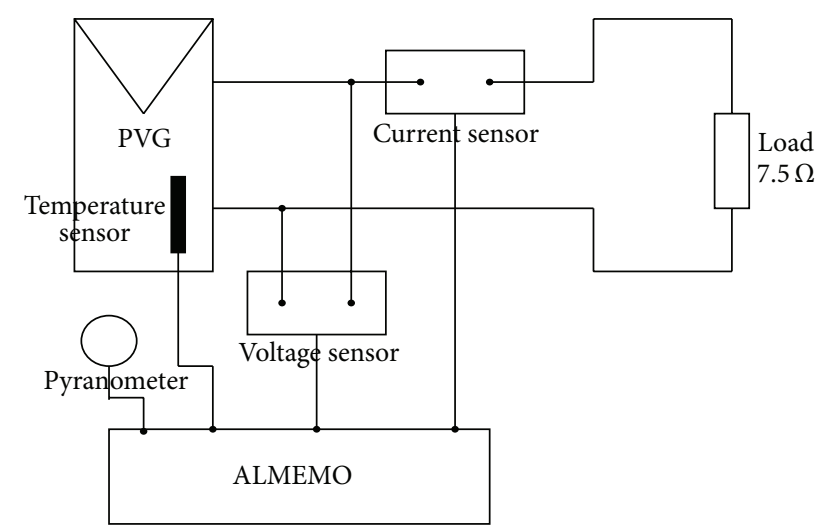

FIGURE 2: Schematic of the experimental installation.

Equation (3) is function of the different photovoltaic parameters: the ideality factor $n$, the series resistance $R_{s}$, and the inverse saturation current of the diode $I_{S}$.

For a photovoltaic array constituted of $N_{s}$ photovoltaic modules in series and $N_{p}$ branches, with $N_{s c}$ cells in series in one photovoltaic module, the current is defined as follows:

$$
\begin{aligned}
I_{\mathrm{pv}} & =N_{P} I_{S}+N_{P} I_{\mathrm{ph}}-\frac{n N_{s c} N_{S} V_{t}}{R_{s}} \\
\cdot & \text { Lambert } W\left[\frac{N_{P} R_{s} I_{S}}{n N_{s c} N_{S} V_{t}}\right. \\
\cdot & \left.\exp \left(\frac{V_{\mathrm{pv}}+N_{P} R_{s} I_{\mathrm{ph}}+N_{P} R_{s} I_{S}}{n N_{s c} N_{S} V_{t}}\right)\right] .
\end{aligned}
$$

2.2. Experiment. Figure 2 shows the schematic of the installation for the experimental data. The different components are

(i) a photovoltaic module with characteristics shown in Table 1,

(ii) a constant resistive load with a resistance equal to $7.5 \Omega$

(iii) one current and one voltage sensors (ALMEMO module for DC voltage and current measurement: $\mathrm{ZA}$ $9900 \mathrm{AB}$ and $\mathrm{ZA} 9901 \mathrm{AB}, 1 \mathrm{kHz}, 12$ bits, $0.1 \mathrm{~s}$, and maximum cycle: $14 \mathrm{hrs}$ ),

(iv) a pyranometer (first class, $285-2800 \mathrm{~nm}, 5-20 \mu \mathrm{V} /$ $\mathrm{W} / \mathrm{m}^{2}, 20-200 \Omega, 0-30 \mathrm{mV}$, and $\max 2000 \mathrm{~W} / \mathrm{m}^{2}$ ) for measuring the irradiance, (v) a temperature sensor (CTN FNA611, -10 to $+90^{\circ} \mathrm{C}$, $20 \mathrm{~s}$ ) for measuring the PV module's surface temperature,

(vi) a data acquisition unit ALMEMO with five inputs.

It is important to note that the temperature sensor is fixed on the surface of the photovoltaic module.

2.3. Extraction Algorithm of PV Module Parameters. The theoretical current $I_{\text {pvth }}$ expressed by the Lambert $W$ function in (5) is used to fit the measured one $I_{\text {meas }}$, by the method of least mean square (LSM), with parameters $n, R_{s}$, and $I_{S}$. The flow chart for the fitting is shown in Figure 3. The first loop with the control variable $j$ is used for reading all the elements of the measured current $I_{\text {meas }}$. The second loop with the control variable $i$ is used for fitting. The convergence criterion is the quadratic difference $\varepsilon$, expressed by the following equation:

$$
\varepsilon=\left|I_{\text {maes }}-I_{\text {pvth }}\right|^{2}
$$

The initial values of the parameters are chosen as small as possible for accurate results: $n_{0}=1.0, R_{s 0}=0.01 \Omega$, and $I_{S 0}=$ $1 \times 10^{-10} \mathrm{~A}$. And steps are $\Delta n=0.001, \Delta R_{s}=0.001 \Omega$, and $\Delta I_{S}=1 \times 10^{-9}$ A. Meanwhile, the highest values of the parameters are $n_{\max }=2.0, R_{s \max }=5 \Omega$, and $I_{s \max }=1 \times 10^{-6} \mathrm{~A}$. The maximum number of iterations is $N_{\text {it }}=200$. This extraction algorithm is implemented by MATLAB software. The accuracy and the good level of the fitting are evaluated from the obtained residuals.

\section{Results and Analysis}

This section presents the recorded meteorological conditions (irradiance and temperature) and the load current. Then, extracted parameters of the PV module are presented with the subsequent discussion. And finally, the extracted parameters were used for the validation of the PV module's modeling using MATLAB/SIMULINK.

3.1. Experimental Results. The measured parameters are the irradiance, the module's surface temperature, the current through the load, and the voltage at its input. The values were recorded on 23 January 2014 from 9:30 AM to 4 PM, with a time cycle of $30 \mathrm{~s}$. The irradiance and the temperature are shown in Figure 4 . The temperature fluctuates during the whole day even if the irradiance does not fluctuate. It means that the module's surface temperature does not depend on the irradiance. And these results confirm the fact that generally in the tropical zone the climatic condition fluctuates permanently.

Figures 5 and 6 show the recorded current through the resistive load. In Figure 5, the current's behaviour is exactly like that of the irradiance. Meanwhile, in Figure 6, even if the temperature fluctuates, the current does not fluctuate like it. This confirms the fact that the photovoltaic current depends only on the irradiance. 


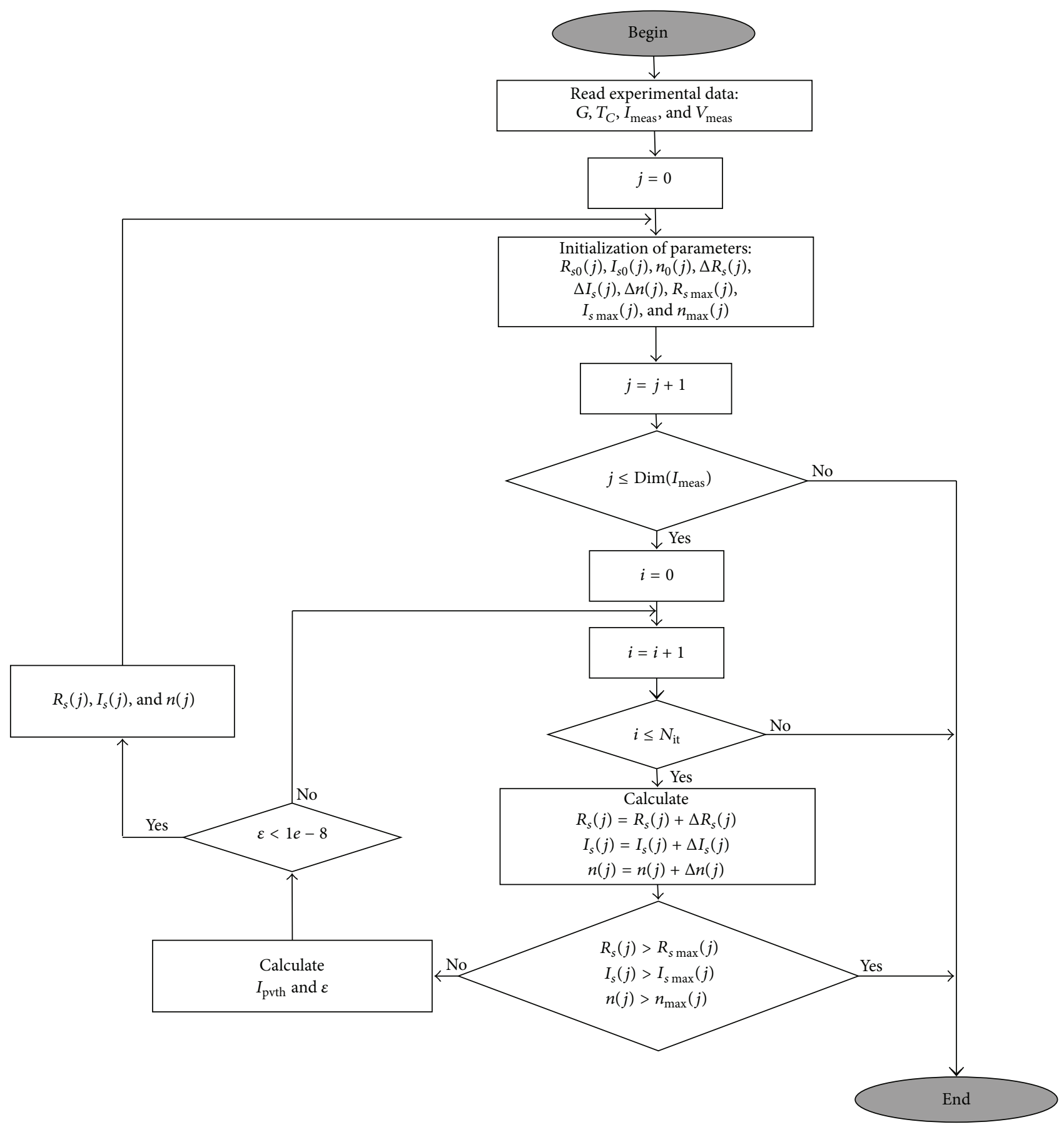

FIgURE 3: Flow chart for the determination of the parameters of a photovoltaic module.

\subsection{Extracted Parameters of the PV Module}

3.2.1. The Ideality Factor. Figures 7 and 8 show the variation of the ideality factor $n$ during the day. This parameter does not depend either on the irradiance or on the temperature, confirming the fact that it can be considered constant and equal to 1.2 for the monocrystalline photovoltaic cells $[2,3$, $14,15]$. However, Figure 9 shows the case when the ideality factor changes and how it can influence the performance of the module. When it increases, the output power decreases.
The standard test conditions $\left(1000 \mathrm{~W} / \mathrm{m}^{2}\right.$ and $\left.25^{\circ} \mathrm{C}\right)$ were used to see the variation with the manufacturer's values.

3.2.2. The Diode Reverse Saturation Current. Figures 10 and 11 show that the diode reverse saturation current changes only with the temperature and is not influenced by the irradiance. As it is shown, from 9:30 AM to 12:30 PM, the irradiance increases without any fluctuation. But the diode reverse saturation current fluctuates, even if it increases, 


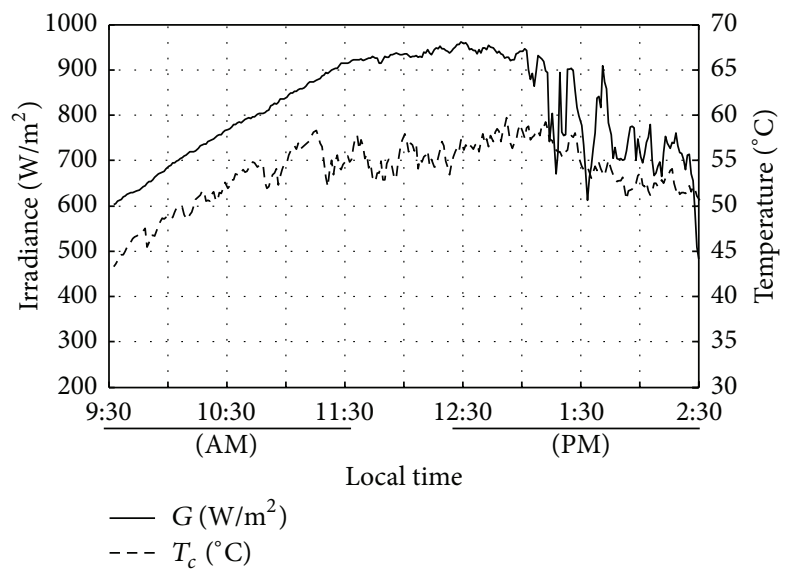

Figure 4: The irradiance and the module's surface temperature recorded on 23 January 2014.

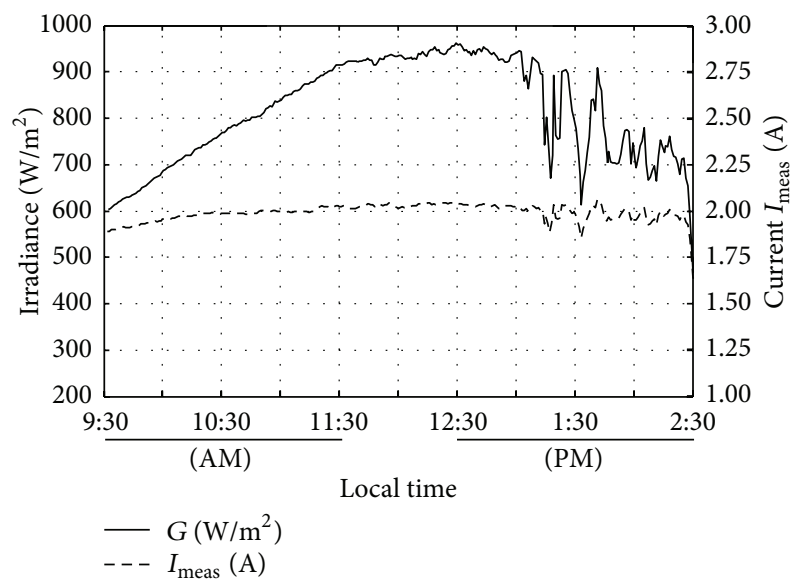

FIGURE 5: The variation of the current through the load with the irradiance.

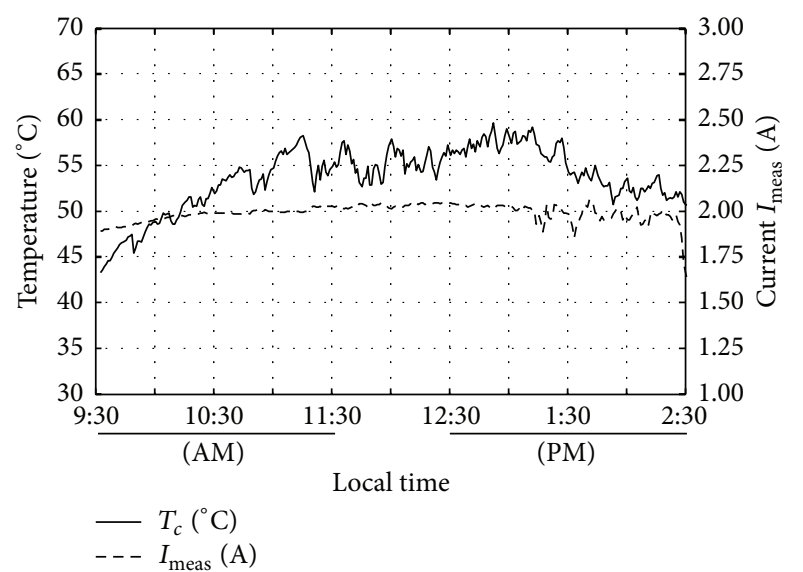

FIgURE 6: The variation of the current through the load with the temperature.

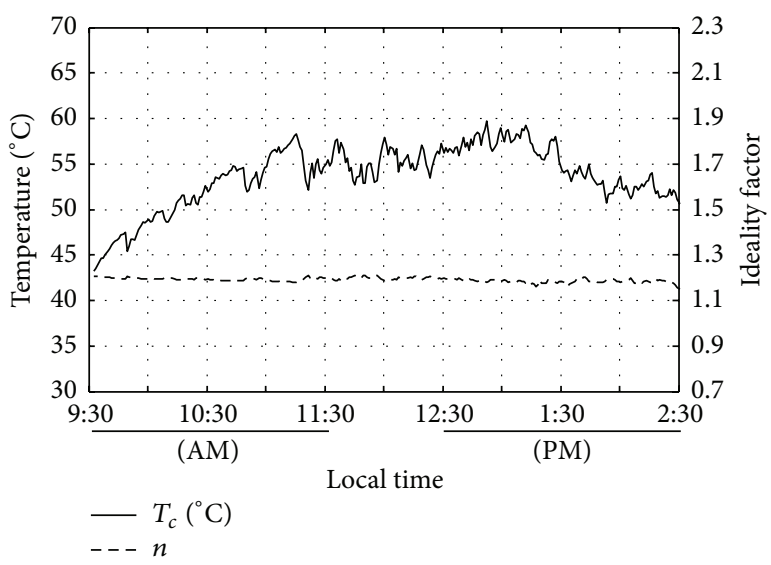

FiguRE 7: Variation of the ideality factor and the temperature.

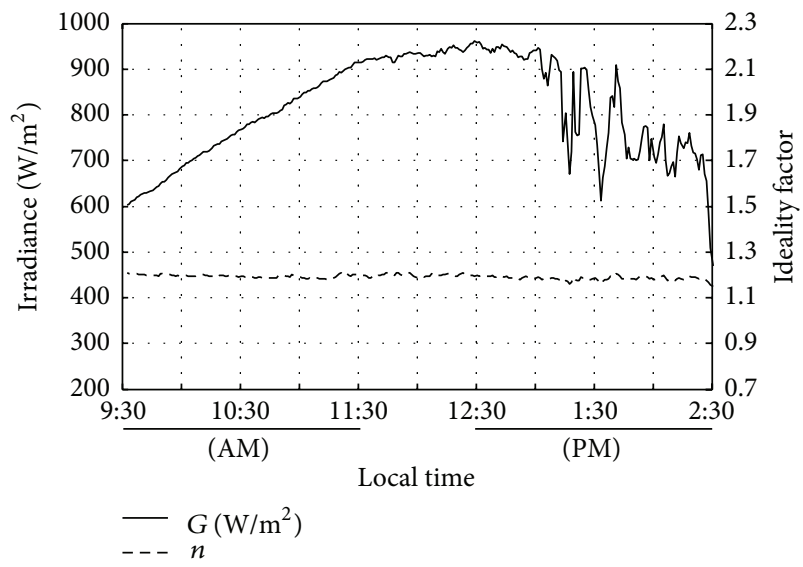

FIGURE 8: Variation of the ideality factor and the irradiance.

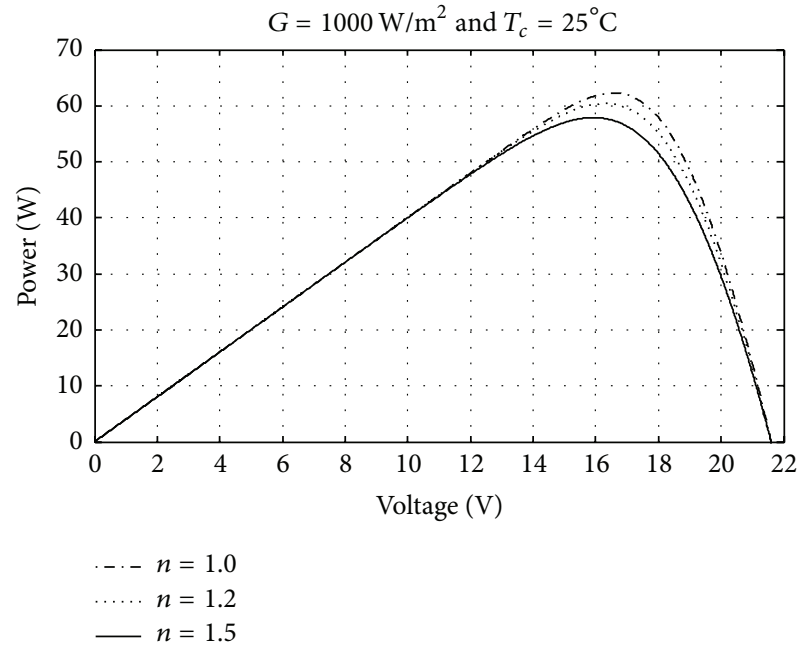

FIGURE 9: Influence of the ideality factor on the $P-V$ characteristic of the photovoltaic module. 


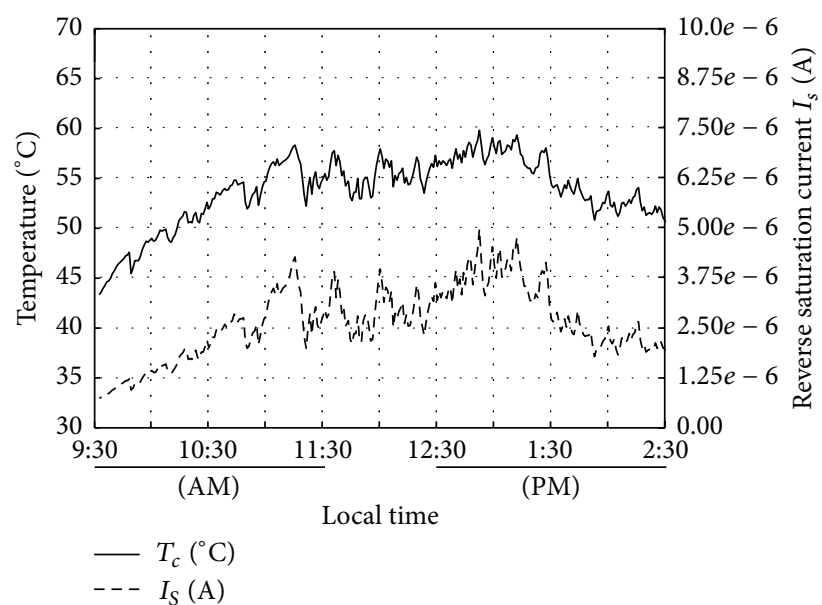

FIgURE 10: Variation of the diode reverse saturation current with temperature during a day.

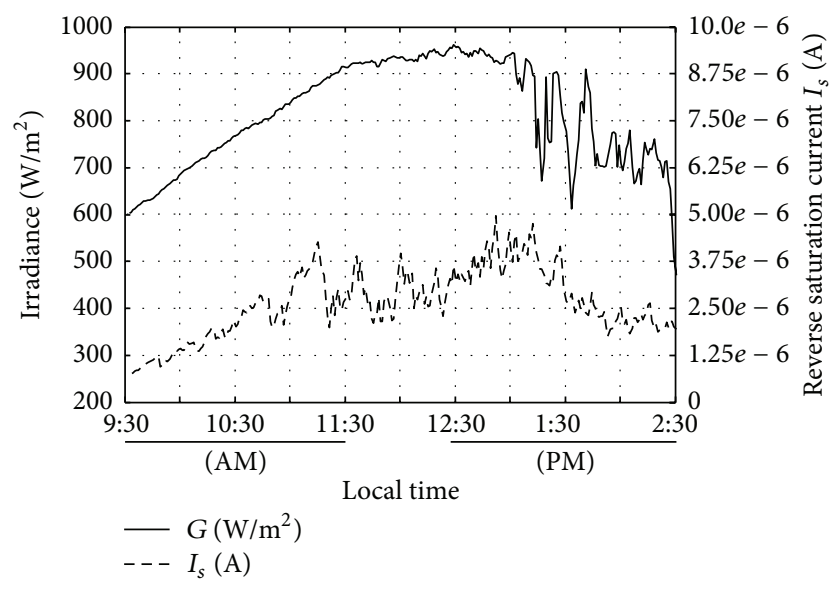

FIGURE 11: Variation of the diode reverse saturation current with irradiance during a day.

in accordance with the temperature which has the same behaviour. And in the afternoon (from 12:30 PM to 2:30 PM), even if the irradiance fluctuates, it is only the fluctuation of the temperature which influences $I_{S}$.

Figure 12 shows the variation of the diode reverse saturation current $I_{S}$ with the temperature. When the temperature increases, $I_{S}$ also increases. For fitting the extracted values of the reverse saturation current $I_{S}$ in function of the temperature, the fitting function is shown by

$$
y(x)=a(x+273)^{3} \exp \left(b\left(c-\frac{1}{x+273}\right)\right)
$$

where $a=2.7941 \times 10^{-15} \mathrm{~A} / \mathrm{K}^{3}, b=10991 \mathrm{~K}$, and $c=$ $0.003355 \mathrm{~K}^{-1}$.

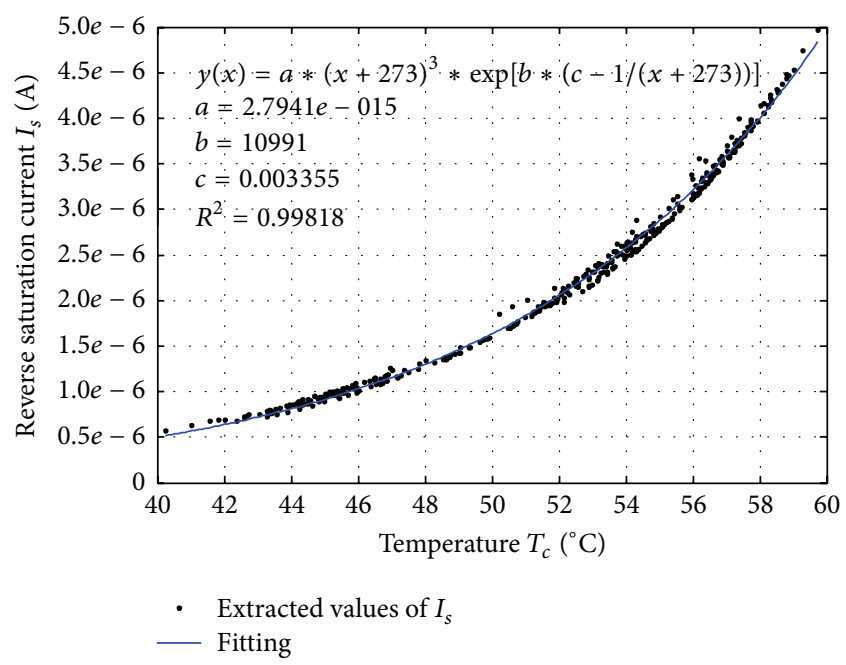

FIGURE 12: Variation of the diode reverse saturation current with temperature.

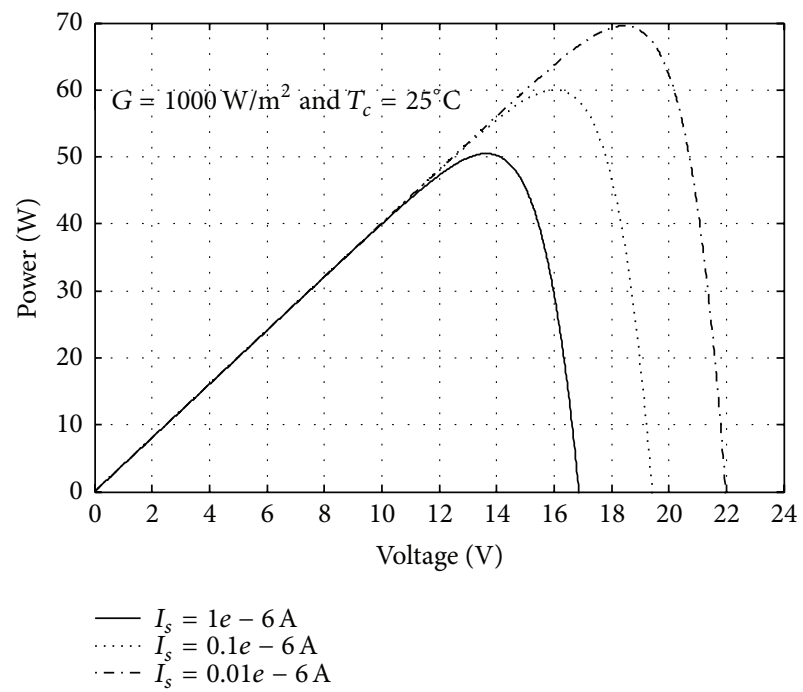

FIGURE 13: Influence of the diode reverse saturation current on the $P-V$ characteristic of the photovoltaic module.

The parameter $c\left(\mathrm{~K}^{-1}\right)$ is the reverse of the reference temperature, $T_{\text {Cref }}=298 \mathrm{~K}$. This equation is the same as the mathematical model given by $(8)$ in the literature $[12,16]$ :

$$
I_{S}=I_{\text {Sref }}\left(\frac{T_{C}}{T_{\text {Cref }}}\right)^{3} \exp \left[\frac{q E_{g}}{n k}\left(\frac{1}{T_{\text {Cref }}}-\frac{1}{T_{C}}\right)\right],
$$

where $I_{\text {Sref }}=7.39 \times 10^{-8} \mathrm{~A}$, the diode reverse saturation current at the standard conditions $\left(T_{C}=T_{\text {Cref }}=298 \mathrm{~K}\right)$, and $q E_{g} / n k=b=10991$.

Figure 13 shows the influence of the diode reverse saturation current on the output power of the photovoltaic module. When $I_{S}$ increases, the voltage decreases and consequently, the output power decreases. The output current of the photovoltaic module is not influenced by the inverse saturation current. The standard test conditions $\left(1000 \mathrm{~W} / \mathrm{m}^{2}\right.$ and $\left.25^{\circ} \mathrm{C}\right)$ were used to see the variation with the manufacturer's values. 


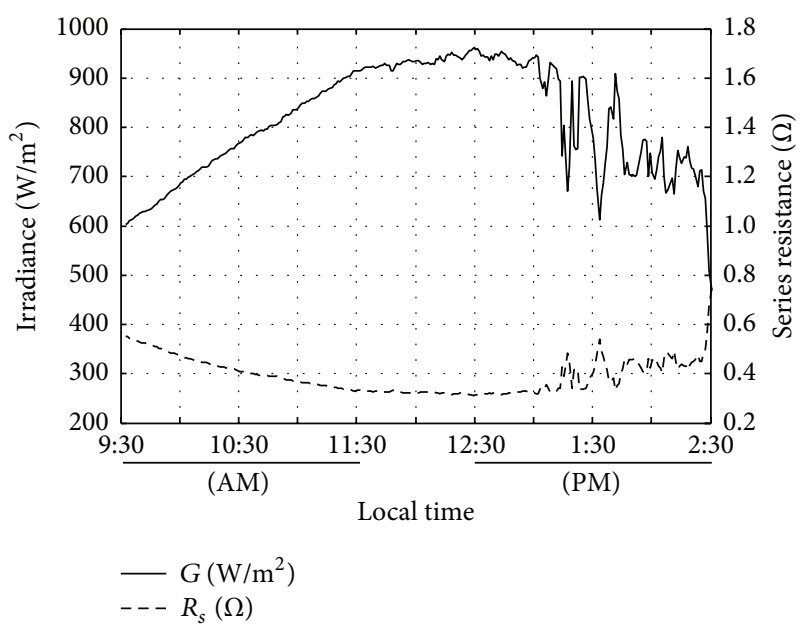

FIGURE 14: Variation of the series resistance with irradiance during a day.

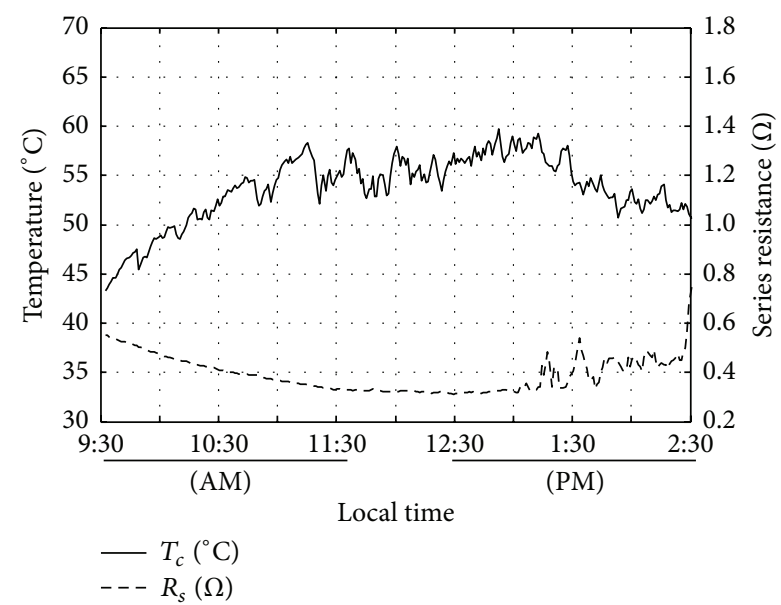

FIGURE 15: Variation of the series resistance with temperature during a day.

3.2.3. The Series Resistance. Figures 14 and 15 show the behaviour of $R_{s}$ during a day. From 9:30 AM to 12:30 PM, $R_{s}$ does not fluctuate like the irradiance, even if the temperature fluctuates. It is in the afternoon (from 12:30 PM to 2:30 PM) when $R_{s}$ begins to fluctuate with the irradiance proving widely that it depends closely on the irradiance.

Figure 16 shows the variation of the series resistance with the irradiance. It is clear that when the irradiance increases, the series resistance decreases in accordance with the result obtained by $[1-3,14-20]$. Its value becomes higher at the very low level of irradiance (less than $200 \mathrm{~W} / \mathrm{m}^{2}$ ). The mathematical model can be expressed in function of the irradiance $G$ by

$$
R_{S}=A \exp \left(B \frac{G}{G_{\text {ref }}}\right)+C,
$$

where $A=3.57 \Omega, B=-4.22, G_{\text {ref }}=1000 \mathrm{~W} / \mathrm{m}^{2}$, and $C=$ $0.26 \Omega$. The temperature $T_{C}$ does not appear in this expression of $R_{s}$.

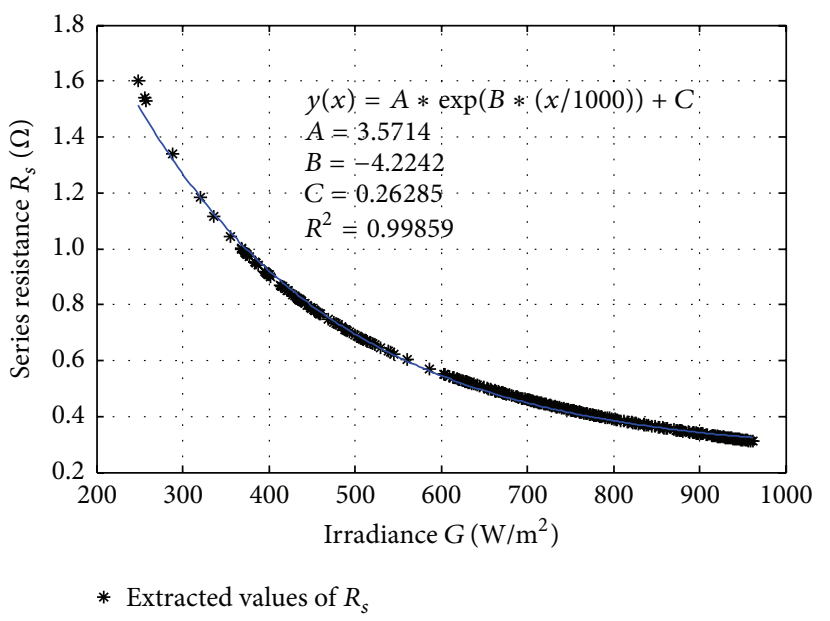

FIGURE 16: Variation of the series resistance with irradiance.

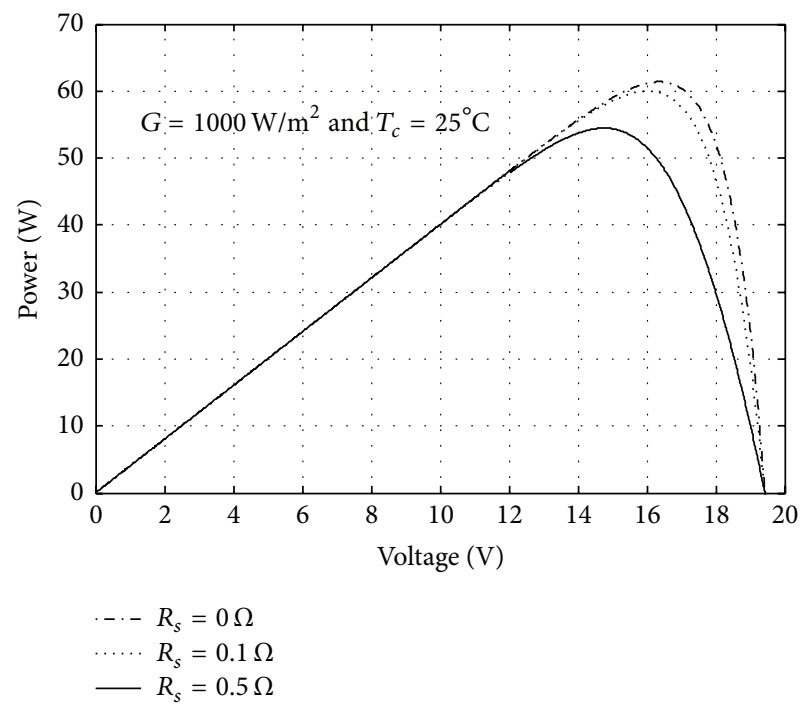

Figure 17: Influence of the series resistance on the $P-V$ characteristic of the photovoltaic module.

Figure 17 shows the effect of the series resistance on the output power of the photovoltaic module. The output power decreases when the series resistance increases. So, it is clear that the performance of the photovoltaic module is best at the higher level of irradiance due to the fact that the series resistance is low. The standard test conditions $\left(1000 \mathrm{~W} / \mathrm{m}^{2}\right.$ and $\left.25^{\circ} \mathrm{C}\right)$ were used to see the variation with the manufacturer's values.

3.3. Validation of the PV Module's Modeling. Figure 18 shows the simulation model of the photovoltaic system. The input parameters are the measured photovoltaic module's surface temperature (in degree Celsius), the measured irradiance (in $\mathrm{W} / \mathrm{m}^{2}$ ), the extracted series resistance (in $\Omega$ ), the extracted ideality factor, and the extracted diode reverse saturation current (in A). The output is the current through the resistive load. For the simulation with the literature parameters, 


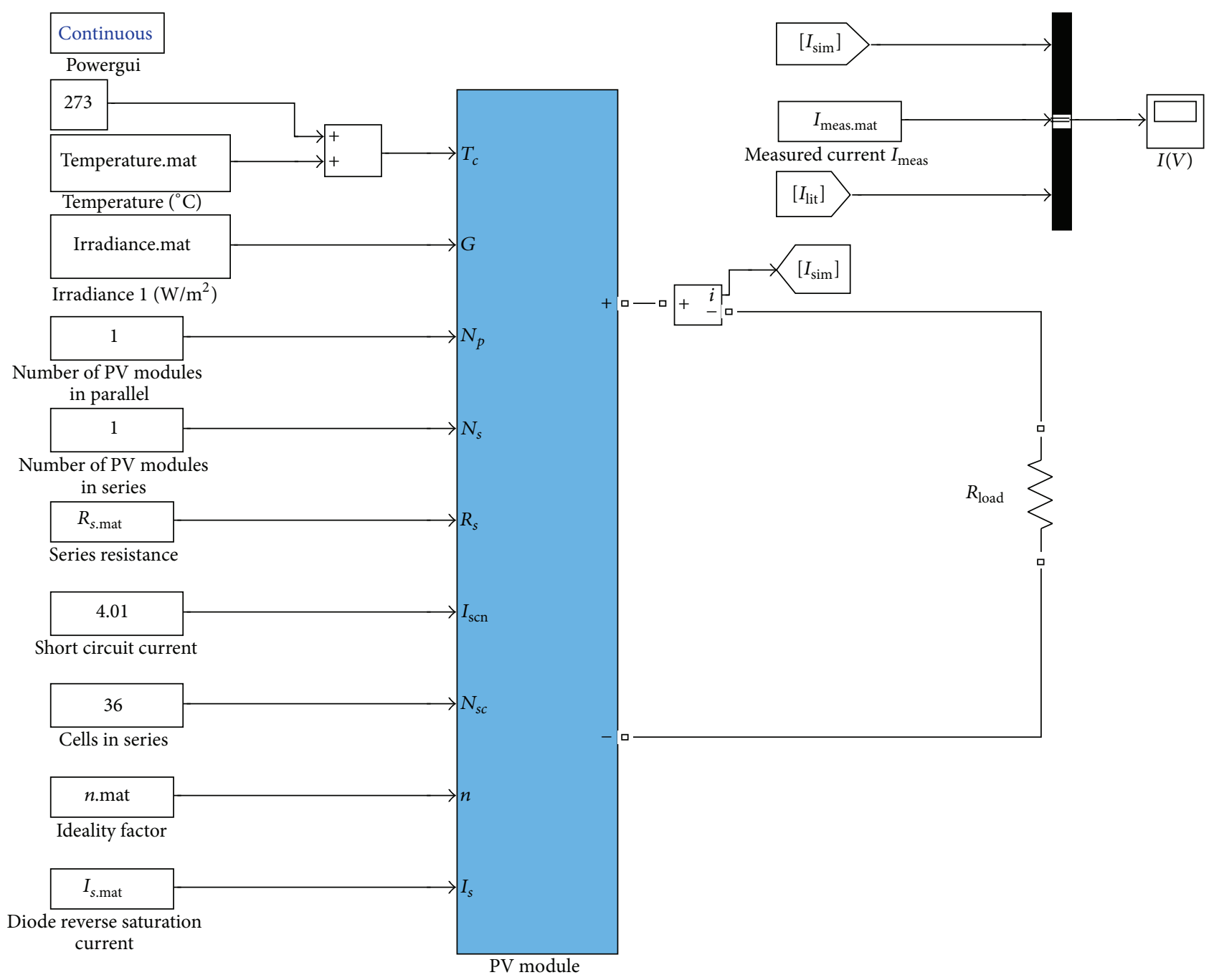

FIGURE 18: SIMULINK model of the photovoltaic system.

the measured irradiance and temperature are used, but the series resistance is $R_{s}=2.1 \Omega$, the ideality factor is $n=1.2$, and the diode reverse saturation current is defined by ( 8 ) with $I_{\text {Sref }}=7.39 \cdot 10^{-8}$ A $[6,11,17]$.

Figure 19 shows the output current of the photovoltaic generator. The first one is the measured current $I_{\text {meas }}$ during day 23 January 2014 at Ngaoundere, Cameroon. The second one is the simulated current $I_{\text {sim }}$ with MATLAB/SIMULINK, using the extracted parameters $\left(n, R_{s}\right.$, and $\left.I_{S}\right)$. And the last one is the simulated current $I_{\text {lit }}$ with MATLAB/SIMULINK, using the consideration of the literature. The results confirm the fact that the parameters such as series resistance and inverse saturation current cannot be considered as constant. If so, the simulated result will be too far from the real system as it is the case in Figure 19. With the extracted parameters, the module's electrical model used for the simulation with MATLAB/SIMULINK is really similar to the real one functioning under the same climatic conditions. So the results of the simulations will accurately be the behaviour of the real system under the normal climatic conditions.

\section{Conclusion}

This paper presents a new method for extracting the different parameters of a monocrystalline silicon solar cell. Modeled by a one diode model with three parameters to be determined (the diode reverse saturation current, the series resistance, and the ideality factor of the $P-N$ junction), a fitting based on the least square method is used to extract these parameters from experimental data. The results confirm that the diode reverse saturation current $I_{S}$ effectively depends on the temperature and the mathematical expression obtained in the literature has been validated. The diode ideality factor, $n$, changes less with the weather conditions. The series resistance, $R_{s}$, depends essentially on the irradiance. The mathematical expression of the series resistance has been obtained. For the verification of the effectiveness of these results, the PV module has been modeled with MATLAB/SIMULINK. The input parameters for the simulations are the recorded irradiance and surface temperature, the determined PV parameters $\left(R_{s}, I_{S}\right.$, and $\left.n\right)$. 


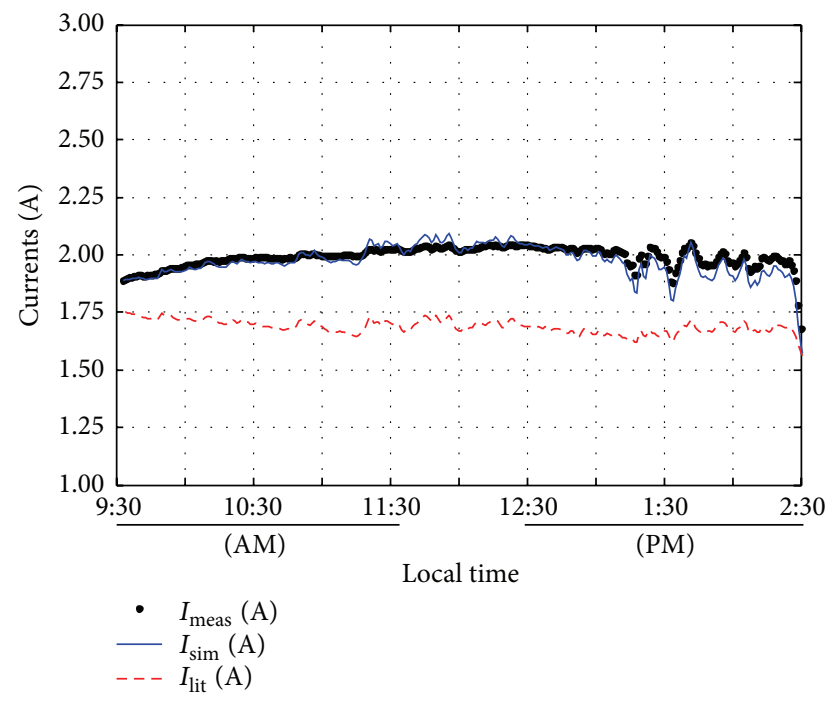

FIGURE 19: Output currents: measured $\left(I_{\text {meas }}\right)$ and simulated $\left(I_{\text {sim }}\right)$ and from literature $\left(I_{\text {lit }}\right)$.

The recorded load current has been also loaded in the SIMULINK model for comparison. For the comparison with the literature results, the same PV module model has been simulated as inputs: the recorded irradiance and temperature, a constant diode ideality factor $(n=1.2)$, a constant series resistor $\left(R_{s}=2.1 \Omega\right)$, and the diode reverse saturation current expression. The results show that the PV module modeled with the variable PV parameters is more accurate than the one modeled with the constant series resistance and the constant diode ideality factor. These simulation results show the real behaviour of the PV module under the normal operating conditions. Consequently, the obtained model can be used for the extraction of the maximum power of the PV module, under the normal weather conditions.

\section{Conflict of Interests}

The authors declare that there is no conflict of interests regarding the publication of this paper.

\section{References}

[1] D. Séra, Real-time modelling, diagnostics and optimised MPPT for residential $P V$ systems [Partial Fulfilment for the degree of Doctor of Philosophy in Electrical Engineering], Aalborg University Institute of Energy Technology, January 2009.

[2] M. A. Green, K. Emery, Y. Hishikawa, and W. Warta, "Solar cell efficiency tables (version 37)," Progress in Photovoltaics: Research and Applications, vol. 19, no. 1, pp. 84-92, 2011.

[3] J. Cubas, S. Pindado, and C. de Manuel, "Explicit expressions for solar panel equivalent circuit parameters based on analytical formulation and the lambert w-function," Energies, vol. 7, no. 7, pp. 4098-4115, 2014.

[4] F. A. Ghani, Investigation into the effects of flow distribution on the photovoltaic performance of a building integrated photovoltaic/thermal solar collector [Ph.D. thesis], University of Waikato, Hamilton, New Zealand, 2013.
[5] T. Ikegami, T. Maezono, F. Nakanishi, Y. Yamagata, and K. Ebihara, "Estimation of equivalent circuit parameters of PV module and its application to optimal operation of PV system," Solar Energy Materials \& Solar Cells, vol. 67, no. 1-4, pp. 389-395, 2001.

[6] B. Mohamed, Modélisation des systèmes énergétiques photovoltaïques et éoliens: intégration dans un système hybride basse tension [Thèse de Doctorat], University of Abou Bekr Belkaï, Tlemcen, Algeria, 2013.

[7] W. Gong and Z. Cai, Parameter Extraction of Solar Cell Models Using Repaired Adaptative Differential Evolution, Elsevier, 2013.

[8] C. Saravana and M. A. Panneerselvan, "A comprehensive analysis for extraction single-diode PV model parameters by hybrid GA-PSO algorithm," International Journal of Computer Applications, vol. 78, no. 8, 2013.

[9] J. Bastidas, C. Ramos, and E. Franco, "Modeling and parameter calculation of photovoltaic fields in irregular weather conditions," Ingenieria, vol. 17, no. 1, pp. 37-48, 2012.

[10] M. R. AlRashidi, K. M. El-Naggar, and M. F. AlHajri, "Parameters rstimation of double diode solar cell model," International Journal of Electrical, Robotics, Electronics and Communications Engineering, vol. 7, no. 2, pp. 98-101, 2013.

[11] K. Ishaque, Z. Salam, H. Taheri, and Syafaruddin, "Modeling and simulation of photovoltaic (PV) system during partial shading based on a two-diode model," Simulation Modelling Practice and Theory, vol. 19, no. 7, pp. 1613-1626, 2011.

[12] G. H. Yordanov, O. M. Midtgård, and T. O. Saetre, "Two-diode model revisited: parameters extraction from semi-log plots of I-V data," in Proceedings of the 25th European Photovoltaic Solar Energy Conference and Exhibition/5th World Conference on Photovoltaic Energy Conversion, pp. 4156-4163, Valencia, Spain, September 2010.

[13] Y.-L. Wang, Y.-Z. Sun, L.-L. Peng, and Y. Xu, "Parameter extraction for photovoltaic module based on Lambert $W$ function," Acta Physica Sinica, vol. 61, no. 24, Article ID 248402, 6 pages, 2012.

[14] F. Ghani, M. Duke, and J. Carson, "Numerical calculation of series and shunt resistance of a photovoltaic cell using the Lambert W-function: experimental evaluation," Solar Energy, vol. 87, no. 1, pp. 246-253, 2013.

[15] M. Chegaar, Z. Ouennoughi, F. Guechi, and H. Langueur, "Determination of solar cells parameters under illuminated conditions," Journal of Electron Devices, vol. 2, pp. 17-21, 2003.

[16] M. Bencherif and A. Chermitti, "New method to assess the losses parameters of the photovoltaic modules," International Journal of Engineering and Advanced Technology, vol. 2, no. 1, 2012.

[17] V. Khanna, B. K. Das, and D. Bisht, "Matlab/simelectronics models based study of solar cells," International Journal of Renewable Energy Research, vol. 3, no. 1, pp. 30-34, 2013.

[18] F. Ghani, M. Duke, and J. Carson, "Numerical calculation of series and shunt resistances and diode quality factor of a photovoltaic cell using the Lambert $W$-function," Solar Energy, vol. 91, pp. 422-431, 2013.

[19] M. Kamta and A. Dandoussou, "An experiment-based approach for improving the photovoltaic power supply system performance by matching impedance," International Review of Automatic Control, vol. 5, no. 5, pp. 630-637, 2012.

[20] F. Khan, S. N. Singh, and M. Husain, "Effect of illumination intensity on cell parameters of a silicon solar cell," Solar Energy Materials \& Solar Cells, vol. 94, no. 9, pp. 1473-1476, 2010. 


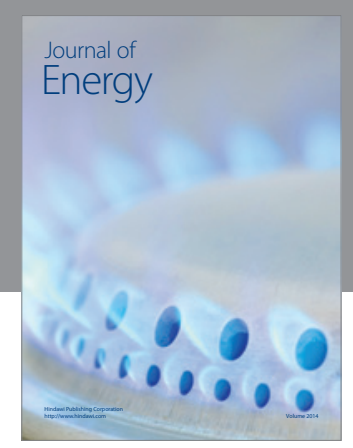

Journal of

Industrial Engineering
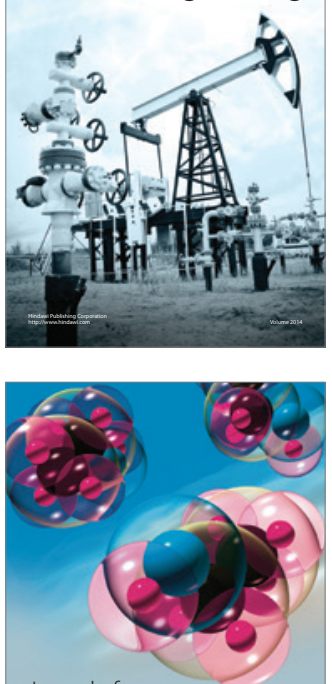

Fuels
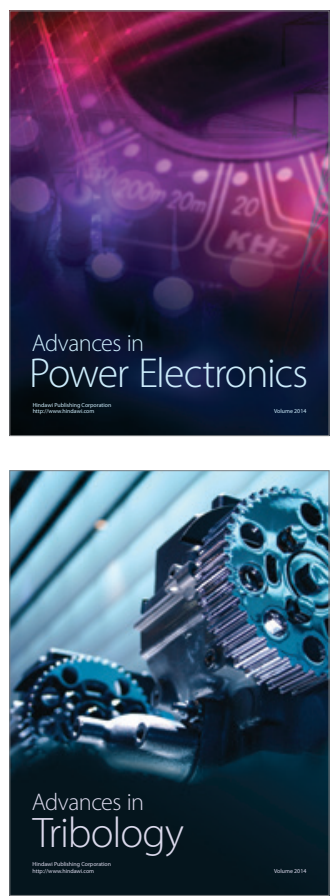

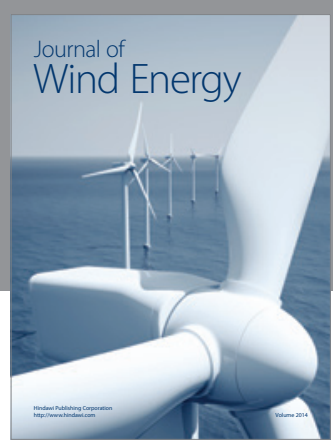

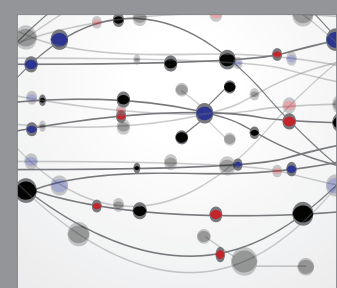

The Scientific World Journal

Submit your manuscripts at http://www.hindawi.com

Journal of

Structures
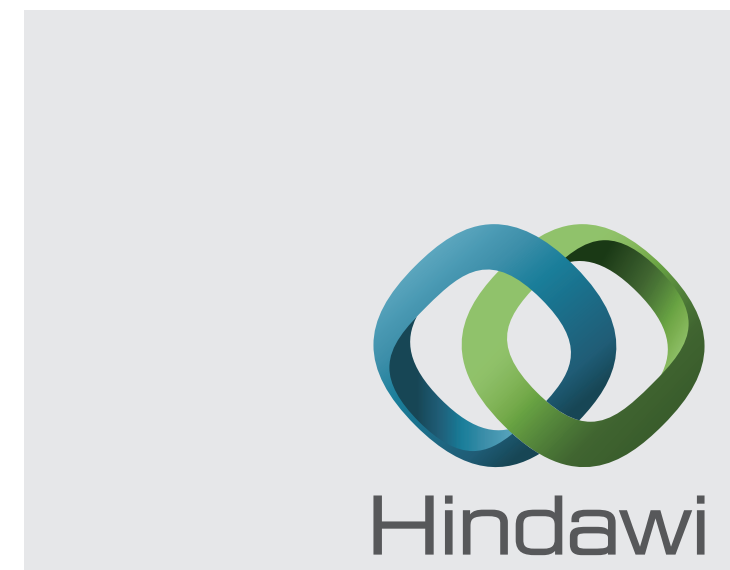

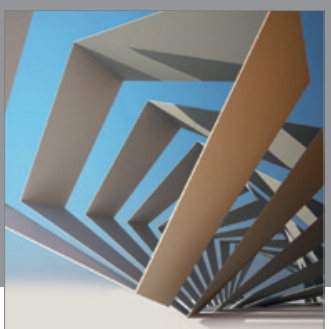

Rotating

Machinery
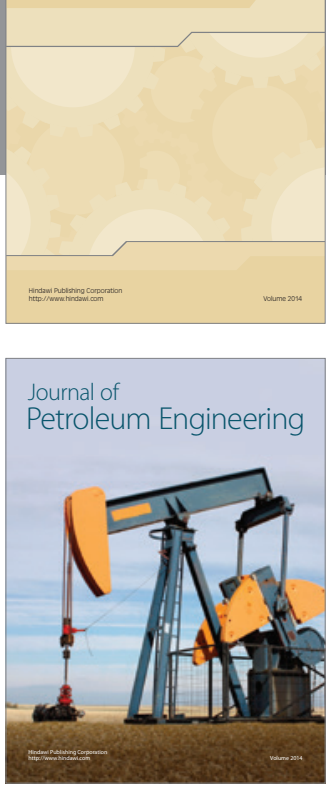

Journal of

Solar Energy
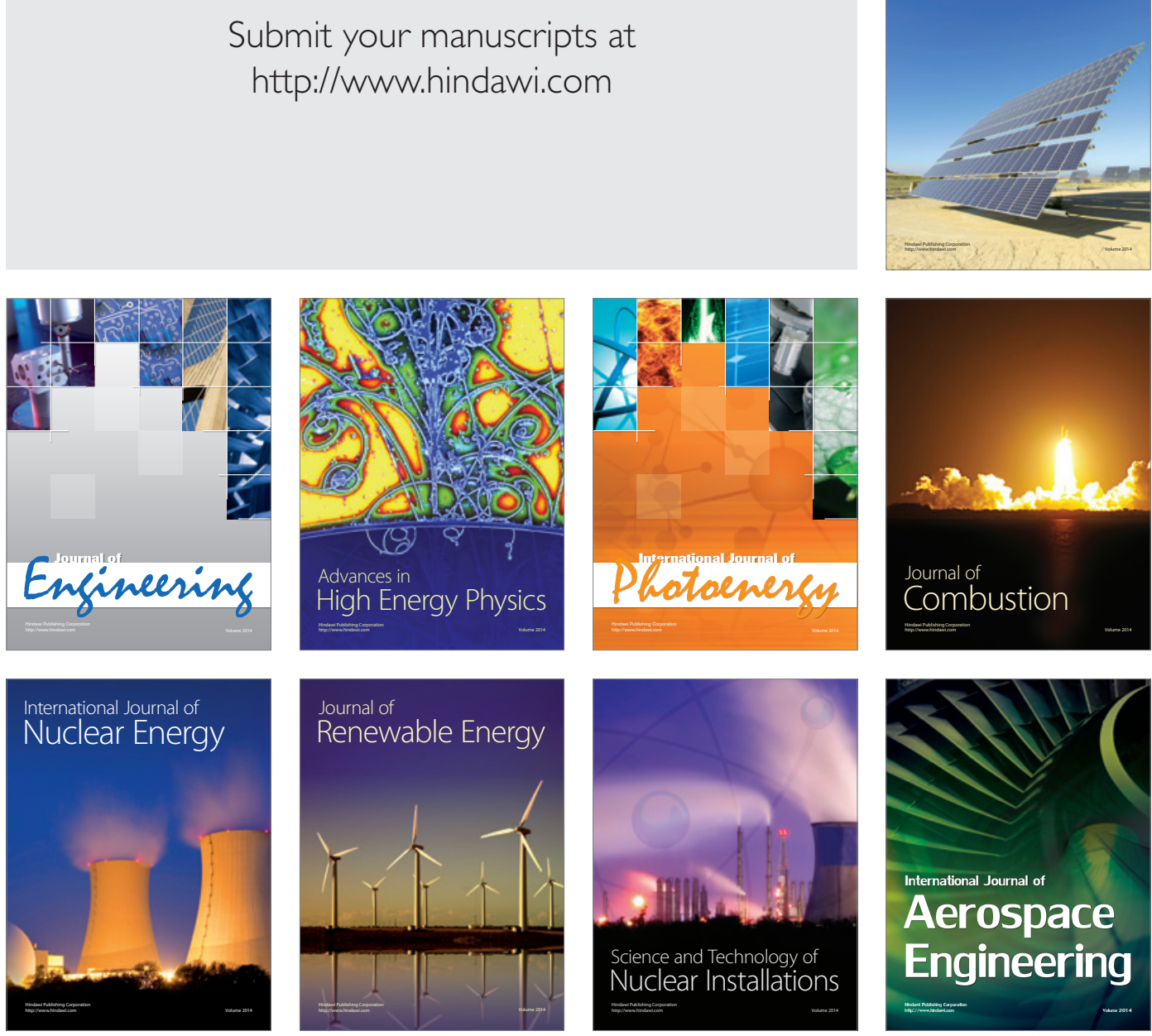